\title{
Optical and Scintillation Properties of Nd-doped Strontium Yttrate Single Crystals
}

\author{
Hiroyuki Fukushima, ${ }^{*}$ Masaki Akatsuka, Hiromi Kimura, \\ Daichi Onoda, Daiki Shiratori, Daisuke Nakauchi, \\ Takumi Kato, Noriaki Kawaguchi, and Takayuki Yanagida \\ Division of Materials Science, Nara Institute of Science and Technology, \\ 8916-5, Ikoma, Nara 630-0192, Japan
}

(Received January 29, 2021; accepted May 20, 2021)

Keywords: photoluminescence, scintillation, single crystal, floating zone, Nd-doped $\mathrm{SrY}_{2} \mathrm{O}_{4}$

$\mathrm{Nd}: \mathrm{SrY}_{2} \mathrm{O}_{4}$ single crystals were successfully synthesized by the floating zone method, and their photoluminescence (PL) and scintillation properties were investigated. The X-ray diffraction patterns of synthesized $\mathrm{Nd}: \mathrm{SrY}_{2} \mathrm{O}_{4}$ demonstrate no impurity phase. Under X-ray irradiation, the samples show scintillation with sharp emission lines at around 900, 1064, and $1300 \mathrm{~nm}$ due to the $4 \mathrm{f}-4 \mathrm{f}$ transitions of $\mathrm{Nd}^{3+}$. The PL and scintillation decay time constants were approximately $170-180$ and $200-270 \mu \mathrm{s}$, respectively. The scintillation intensity was proportional to the X-ray dose exposure in the dynamic range from 0.06 to $60 \mathrm{~Gy} / \mathrm{h}$.

\section{Introduction}

Scintillators immediately convert high-energy photons such as gamma or X-rays to visible photons. Scintillators are combined with photodetectors such as photomultiplier tubes (PMTs) or photodiodes for radiation detection. The typical applications of scintillators are medical diagnosis, ${ }^{(1)}$ resource exploration, ${ }^{(2)}$ environmental monitoring, ${ }^{(3)}$ and astrophysics. ${ }^{(4)}$ Most of the present scintillators are doped with rare-earth ions such as $\mathrm{Ce}^{3+}, \mathrm{Pr}^{3+}$, and $\mathrm{Eu}^{2+}$, whose emission wavelengths are suitable for the wavelength sensitivity of common PMTs. Up to now, $\mathrm{Ce}: \mathrm{Lu}_{2} \mathrm{SiO}_{5},{ }^{(5)} \mathrm{Ce}:\left(\mathrm{Lu}_{x} \mathrm{Gd}_{1-x}\right){ }_{2} \mathrm{SiO}_{5},{ }^{(6)} \mathrm{Ce}: \mathrm{Gd}_{3} \mathrm{Al}_{2} \mathrm{Ga}_{3} \mathrm{O}_{12},{ }^{(7)} \mathrm{Pr}: \mathrm{Lu}_{3} \mathrm{Al}_{5} \mathrm{O}_{12},{ }^{\left({ }^{(8)}\right.} \mathrm{Eu}: \mathrm{SrI}_{2}$, ${ }^{\left({ }^{9}\right)}$ and $\mathrm{Eu}: \mathrm{LiCaAlF}_{6}{ }^{(10)}$ have been used as scintillators. Many inorganic materials have also been investigated as novel scintillators. ${ }^{(11-15)}$

In recent years, with the development of near-infrared (NIR) photodetectors, NIR-emitting scintillators have been studied. ${ }^{(16-20)}$ NIR-emitting scintillators are expected to be used in biomedical imaging ${ }^{(21)}$ and dose monitoring in nuclear power plants. ${ }^{(22)}$ In biomedical imaging applications such as radiation therapy, fine particles of NIR-emitting scintillators are incorporated into the target. Emitted NIR photons are transmitted through human tissue, allowing them to be detected outside the body. Cherenkov radiation is often generated in highdose environments such as nuclear power plants. Cherenkov radiation is strong in the UV-blue range, ${ }^{(23)}$ so it is difficult to distinguish scintillation photons of conventional UV-blue

${ }^{*}$ Corresponding author: e-mail: fukushima.hiroyuki.ex8@ms.naist.jp https://doi.org/10.18494/SAM.2021.3324 
scintillators. In such cases, NIR-emitting scintillators are advantageous for high-dose monitoring applications.

In this study, we focus on $\mathrm{SrY}_{2} \mathrm{O}_{4}$ as a host material of NIR-emitting scintillators. $\mathrm{SrY}_{2} \mathrm{O}_{4}$ has high chemical and thermal stability and is expected to be used in field emission displays. ${ }^{(24)}$ To date, rare-earth-doped $\mathrm{SrY}_{2} \mathrm{O}_{4}$ has been studied. ${ }^{(25-28)}$ Some rare-earth-doped materials exhibit luminescence in the NIR region. In particular, Nd-doped materials such as $\mathrm{Nd}_{2} \mathrm{Y}_{3} \mathrm{Al}_{5} \mathrm{O}_{12},{ }^{(29)}$ $\mathrm{YVO}_{4},{ }^{(30)}$ and $\mathrm{LiYF}_{4}{ }^{(31)}$ show strong emission in the NIR range due to the $4 \mathrm{f}-4 \mathrm{f}$ transitions of $\mathrm{Nd}^{3+}$. Therefore, $\mathrm{Nd}$ is a promising luminescence center for NIR-emitting scintillators. On the other hand, to our best knowledge, the photoluminescence (PL) and scintillation properties of $\mathrm{Nd}: \mathrm{SrY}_{2} \mathrm{O}_{4}$ have not been investigated. In this study, $\mathrm{Nd}: \mathrm{SrY}_{2} \mathrm{O}_{4}$ single crystals were synthesized by the floating zone (FZ) method, and their PL and scintillation properties were investigated.

\section{Materials and Methods}

$\mathrm{Nd}: \mathrm{SrY}_{2} \mathrm{O}_{4}$ single crystals were synthesized by the FZ method (FZ-T-12000-X-VPO-PC-YH, Crystal Systems). $\mathrm{SrCO}_{3}(99.99 \%), \mathrm{Y}_{2} \mathrm{O}_{3}(99.99 \%)$, and $\mathrm{Nd}_{2} \mathrm{O}_{3}(99.99 \%)$ in a stoichiometric ratio were measured and mixed using a mortar and pestle. The nominal $\mathrm{Nd}$ concentrations were 0.1 , $0.5,1$, and $2 \%$ with respect to $\mathrm{Y}$ sites. The mixed powder was placed in an alumina crucible then sintered at $1200{ }^{\circ} \mathrm{C}$ for $8 \mathrm{~h}$ to release $\mathrm{CO}_{2}$. The sintered powder was mixed again, then formed into cylindrical rods by applying hydrostatic pressure. The molded rods were sintered at $1400{ }^{\circ} \mathrm{C}$ for $8 \mathrm{~h}$ to obtain the polycrystalline seeds and charge rods. Finally, the rods were loaded into the FZ furnace and crystal growth was conducted with a pulling down rate of $10 \mathrm{~mm} / \mathrm{h}$. Powder X-ray diffraction (XRD) was measured using a diffractometer (Rigaku, MiniFlex600) in the range of $2 \theta=10-80^{\circ}$. A bias voltage of $40 \mathrm{kV}$ and a tube current of $15 \mathrm{~mA}$ were supplied to the $\mathrm{X}$-ray generator, and the $\mathrm{X}$-ray source was $\mathrm{CuK} \alpha$.

The PL excitation and emission contour plots and PL quantum yield $(Q Y)$ were measured using a Quantaurus-QY spectrometer (Hamamatsu Photonics, C11347). The PL decay curves were measured using a Quantaurus-Tau spectrometer (Hamamatsu Photonics, C11367). The X-ray-induced scintillation spectra were measured in our original setup ${ }^{(7)}$ using an Andor DU492A spectrometer with a spectral sensitivity from 650 to $1650 \mathrm{~nm}$. The relationship between scintillation signal intensity and X-ray exposure dose from 0.06 to $60 \mathrm{~Gy} / \mathrm{h}$ was investigated as a detector property, where the measurement system was our original setup shown in Fig. 1. The X-ray tube voltage was $40 \mathrm{kV}$ and several different currents were applied to change the X-ray exposure dose. The NIR light emitted from the sample was guided to an InGaAs PIN photodiode (Hamamatsu Photonics, G12180-250A) through an optical fiber (Thorlabs, FP600ERT). The length and core diameter of the optical fiber were $5 \mathrm{~m}$ and $600 \mu \mathrm{m}$, respectively. The PIN photodiode was mounted on a heat dissipator (Hamamatsu Photonics, A3179), which was connected to a temperature controller (Hamamatsu Photonics, C1103) to cool the PIN photodiode to about $253 \mathrm{~K}$. Finally, the electrical signals from the PIN photodiode were measured by a picoammeter (Keysight, B2985A). The X-ray-induced scintillation decay curves were investigated using our original setup. ${ }^{(32)}$ A PMT (Hamamatsu Photonics, H7421-50) was used in this measurement and the wavelength sensitivity was $380-900 \mathrm{~nm}$. 


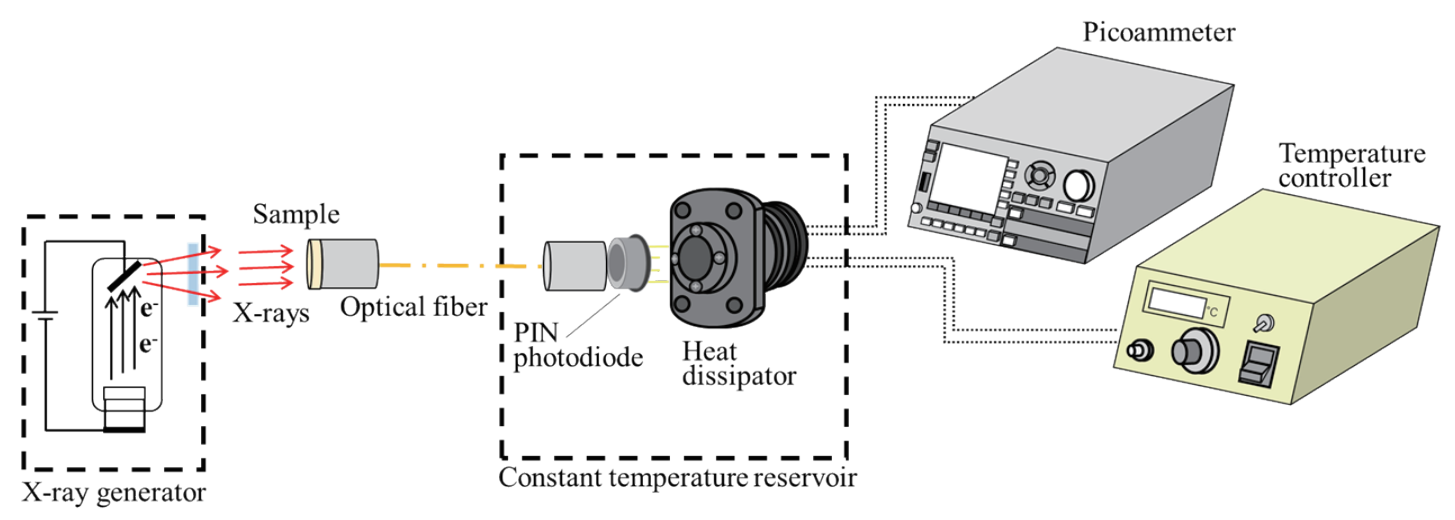

Fig. 1. (Color online) Schematic drawing of current measurement system.

\section{Results and Discussion}

The Nd:SrY ${ }_{2} \mathrm{O}_{4}$ single crystals were successfully synthesized. The typical diameter and length of the as-synthesized single crystals were approximately $5 \mathrm{~mm}$ and $15-20 \mathrm{~mm}$, respectively. Figure 2 shows the appearance of the $\mathrm{Nd}: \mathrm{SrY}_{2} \mathrm{O}_{4}$ single crystals after cutting and polishing. All the crystals are transparent, and the pale blue color is due to the absorption of $4 \mathrm{f}-$ $4 \mathrm{f}$ transitions of $\mathrm{Nd}^{3+}$.

Figure 3 shows the XRD patterns of the $\mathrm{Nd}: \mathrm{SrY}_{2} \mathrm{O}_{4}$ crystals and a reference pattern (COD. 2002282). The obtained XRD patterns were consistent with the reference pattern, and no impurity phase was observed. Thus, the synthesized $\mathrm{Nd}: \mathrm{SrY}_{2} \mathrm{O}_{4}$ had a single phase of $\mathrm{SrY}_{2} \mathrm{O}_{4}$, which had an orthorhombic symmetry with a Pnam space group. ${ }^{(33)}$

Figure 4 shows the PL excitation/emission contour map of the $0.5 \% \mathrm{Nd}: \mathrm{SrY}_{2} \mathrm{O}_{4}$ as a representative sample. The color indicates the emission intensity, and the vertical and horizontal axes are the excitation and emission wavelengths, respectively. The $0.5 \% \mathrm{Nd}: \mathrm{SrY}_{2} \mathrm{O}_{4}$ exhibited sharp emission lines at around $900 \mathrm{~nm}$ under some excitation wavelengths, and the emission excited at around $600 \mathrm{~nm}$ had the strongest intensity among the observed emissions. The spectral feature was close to the typical emission of the $4 \mathrm{f}-4 \mathrm{f}$ transitions of $\mathrm{Nd}^{3+}$. (16) The other $\mathrm{Nd}: \mathrm{SrY}_{2} \mathrm{O}_{4}$ samples exhibited similar spectra with different intensities. The PL $Q Y$ s of the $0.1,0.5,1$, and $2 \%$ $\mathrm{Nd}: \mathrm{SrY}_{2} \mathrm{O}_{4}$ were $36.8,34.3,22.3$, and $13.0 \%$, respectively. The $0.1 \% \mathrm{Nd}: \mathrm{SrY}_{2} \mathrm{O}_{4}$ showed the highest PL $Q Y$ among the samples, and the PL $Q Y$ decreased with increasing Nd concentration.

Figure 5 illustrates the PL decay curves of the $\mathrm{Nd}: \mathrm{SrY}_{2} \mathrm{O}_{4}$ samples. The excitation and monitoring wavelengths were 600 and $875 \mathrm{~nm}$, respectively. The observed decay curves were well fitted by a single exponential decay function, and the observed decay time constants are listed in Table 1 . The decay time constants were about $170-180 \mu \mathrm{s}$, which are typical values for the $4 \mathrm{f}-4 \mathrm{f}$ transitions of $\mathrm{Nd}^{3+} .{ }^{(34)}$ The results support the attribution of the emission observed at around $900 \mathrm{~nm}$ to the $4 \mathrm{f}-4 \mathrm{f}$ transitions of $\mathrm{Nd}^{3+}$.

Figure 6 shows the X-ray-induced scintillation spectra of the $\mathrm{Nd}: \mathrm{SrY}_{2} \mathrm{O}_{4}$ samples in the ranges of 170-690 nm (inset) and 650-1650 nm. Sharp emission lines appeared at around $360 \mathrm{~nm}\left({ }^{4} \mathrm{D}_{3 / 2} \rightarrow{ }^{4} \mathrm{I}_{9 / 2}\right), 390 \mathrm{~nm}\left({ }^{4} \mathrm{P}_{3 / 2} \rightarrow{ }^{4} \mathrm{I}_{9 / 2}\right), 420 \mathrm{~nm}\left({ }^{2} \mathrm{D}_{5 / 2} \rightarrow{ }^{4} \mathrm{I}_{9 / 2}\right), 450 \mathrm{~nm}\left({ }^{4} \mathrm{D}_{3 / 2} \rightarrow{ }^{4} \mathrm{I}_{11 / 2}\right)$, 


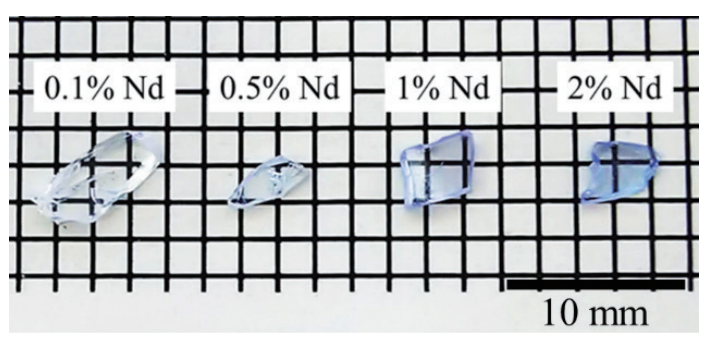

Fig. 2. (Color online) Photograph of $\mathrm{Nd}: \mathrm{SrY}_{2} \mathrm{O}_{4}$ single crystals.

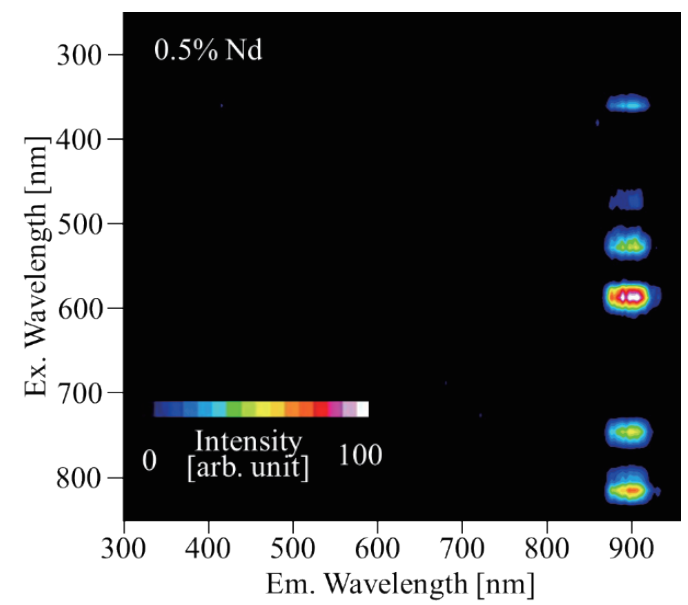

Fig. 4. (Color online) PL excitation wavelength (vertical axis) and emission wavelength (horizontal axis) contour map of $0.5 \% \mathrm{Nd}: \mathrm{SrY}_{2} \mathrm{O}_{4}$.

Table 1

PL decay time constants of $\mathrm{Nd}: \mathrm{SrY}_{2} \mathrm{O}_{4}$.

\begin{tabular}{cc}
\hline Nd concentration $(\%)$ & $\tau(\mu \mathrm{s})$ \\
\hline 0.1 & 173.5 \\
0.5 & 171.5 \\
1 & 178.6 \\
2 & 177.5 \\
\hline
\end{tabular}

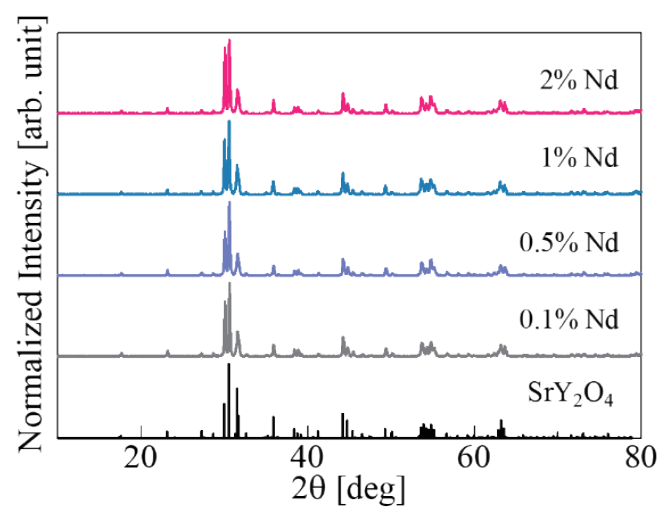

Fig. 3. (Color online) XRD patterns of $\mathrm{Nd}: \mathrm{SrY}_{2} \mathrm{O}_{4}$ and reference pattern (COD. 2002282).

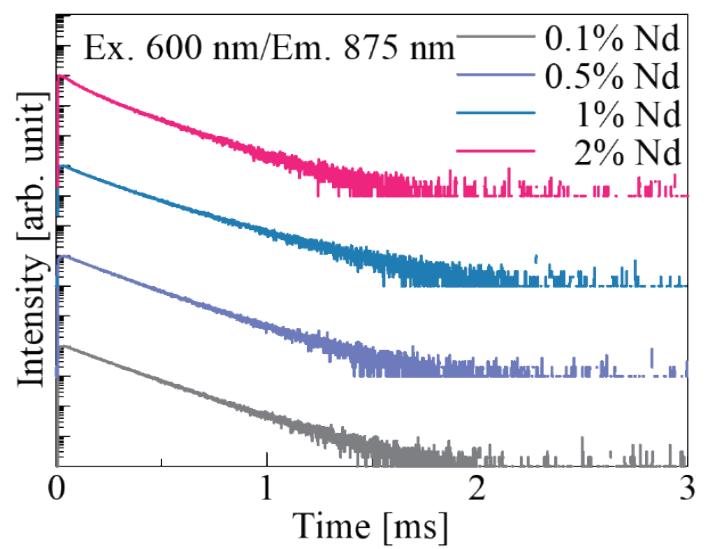

Fig. 5. (Color online) PL decay curves of $\mathrm{Nd}: \mathrm{SrY}_{2} \mathrm{O}_{4}$ samples monitored at $875 \mathrm{~nm}$ under excitation at 600 nm.

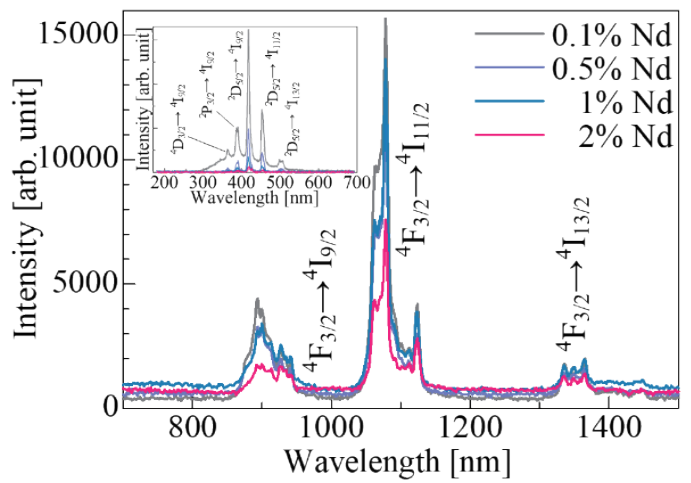

Fig. 6. (Color online) X-ray-induced scintillation spectra of $\mathrm{Nd}: \mathrm{SrY}_{2} \mathrm{O}_{4}$ samples in NIR range and UVvisible range (inset). 
$500 \mathrm{~nm}\left({ }^{4} \mathrm{D}_{3 / 2} \rightarrow{ }^{4} \mathrm{I}_{13 / 2}\right), 900 \mathrm{~nm}\left({ }^{4} \mathrm{~F}_{3 / 2} \rightarrow{ }^{4} \mathrm{I}_{9 / 2}\right), 1064 \mathrm{~nm}\left({ }^{4} \mathrm{~F}_{3 / 2} \rightarrow{ }^{4} \mathrm{I}_{11 / 2}\right)$, and $1350 \mathrm{~nm}\left({ }^{4} \mathrm{~F}_{3 / 2} \rightarrow{ }^{4} \mathrm{I}_{13 / 2}\right)$ due to $4 \mathrm{f}-4 \mathrm{f}$ transitions of $\mathrm{Nd}^{3+} .{ }^{3}(16,35)$ The $0.1 \% \mathrm{Nd}: \mathrm{SrY}_{2} \mathrm{O}_{4}$ sample exhibited a broad luminescence peak at $400 \mathrm{~nm}$, and the spectral shape was similar to that of the undoped $\mathrm{SrY}_{2} \mathrm{O}_{4} \cdot{ }^{(36)}$ The strong peak that appeared at around $1064 \mathrm{~nm}$ is well known for its laser applications. ${ }^{(29)}$ The $0.1 \% \mathrm{Nd}: \mathrm{SrY}_{2} \mathrm{O}_{4}$ sample exhibited the highest scintillation intensity among the samples, and the results were consistent with the value of the PL QY. The scintillation intensity decreased with increasing $\mathrm{Nd}$ concentration.

To investigate the properties of the $\mathrm{Nd}: \mathrm{SrY}_{2} \mathrm{O}_{4}$ samples for their use as an X-ray detector, the relationship between the scintillation intensity of the $\mathrm{Nd}: \mathrm{SrY}_{2} \mathrm{O}_{4}$ samples and the X-ray dose exposure was investigated as shown in Fig. 7. The signal intensity was not corrected by consideration of the sample size. All the synthesized samples exhibited good linearity in the range from 0.06 to $60 \mathrm{~Gy} / \mathrm{h}$. No clear signal was observed under $0.01 \mathrm{~Gy} / \mathrm{h}$ irradiation for all the $\mathrm{Nd}: \mathrm{SrY}_{2} \mathrm{O}_{4}$ samples owing to the low signal-to-noise ratio. The lower detection limit of $0.06 \mathrm{~Gy} / \mathrm{h}$ was approximately ten times better than that in a previous study, in which an optical fiber with the same core diameter was used. ${ }^{(37)}$ The system for evaluating X-ray dose exposure worked correctly and had a low detection limit. To the best of our knowledge, this is the first report on the evaluation of X-ray dose exposure using $\mathrm{Nd}: \mathrm{SrY}_{2} \mathrm{O}_{4}$.

Figure 8 illustrates the X-ray-induced scintillation decay curves of the $\mathrm{Nd}: \mathrm{SrY}_{2} \mathrm{O}_{4}$ samples. The observed decay curves were fitted by a sum of two exponential decay functions. Table 2 lists the obtained X-ray-induced scintillation decay time constants of the samples. The faster decay component was attributed to an instrumental response function, which was mainly generated by the direct collisions of X-rays with the photocathode of the PMT. The calculated decay time constants of the slower decay component were about 200-270 $\mu$ s, which are typical values for the $4 \mathrm{f}-4 \mathrm{f}$ transitions of $\mathrm{Nd}^{3+} \cdot{ }^{(19)}$ The decay time constants were independent of the $\mathrm{Nd}$ concentration.

Figure 9 shows the afterglow curves of the $\mathrm{Nd}: \mathrm{SrY}_{2} \mathrm{O}_{4}$ samples. The afterglow levels $(A)$ were calculated using the equation $A=\left(I_{2}-I_{B G}\right) /\left(I_{1}-I_{B G}\right)$, where $I_{1}$ is the average intensity during X-ray exposure, $I_{2}$ is the intensity $20 \mathrm{~ms}$ after stopping the X-ray exposure, and $I_{B G}$ is the

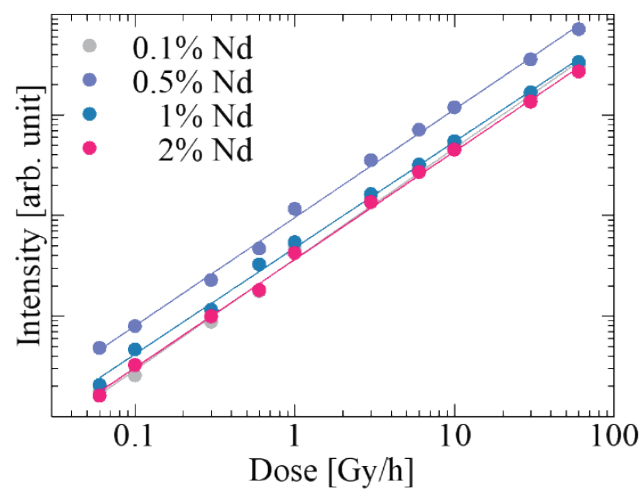

Fig. 7. (Color online) Relationship between scintillation intensity and X-ray dose exposure from 0.06 to $60 \mathrm{~Gy} / \mathrm{h}$.

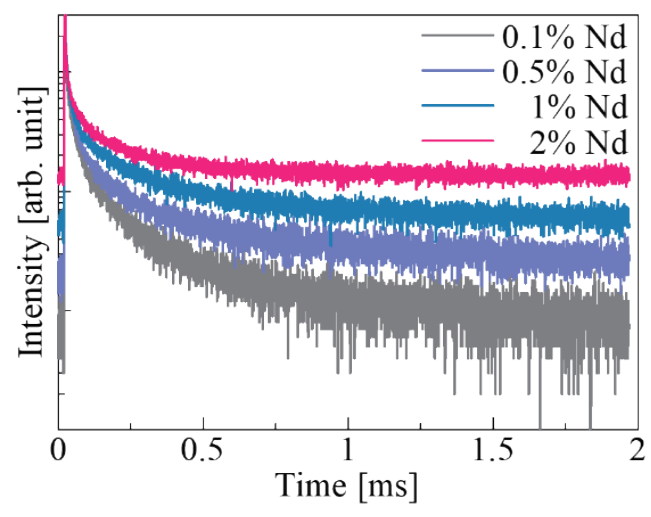

Fig. 8. (Color online) X-ray-induced scintillation decay curves of $\mathrm{Nd}: \mathrm{SrY}_{2} \mathrm{O}_{4}$ samples. 
Table 2

$\mathrm{X}$-ray-induced scintillation decay time constants and afterglow levels of $\mathrm{Nd}: \mathrm{SrY}_{2} \mathrm{O}_{4}$ samples.

\begin{tabular}{ccc}
\hline Nd concentration $(\%)$ & $\tau(\mu \mathrm{s})$ & $A(\mathrm{ppm})$ \\
\hline 0.1 & 194.3 & 513 \\
0.5 & 268.2 & 246 \\
1 & 252.1 & 428 \\
2 & 242.3 & 314 \\
\hline
\end{tabular}

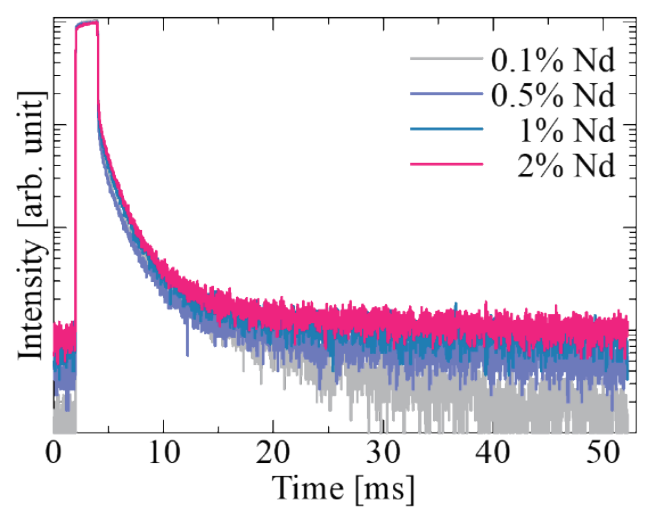

Fig. 9. (Color online) Afterglow curves of $\mathrm{Nd}: \mathrm{SrY}_{2} \mathrm{O}_{4}$ samples.

background intensity. The calculated afterglow levels are listed in Table 2. The $0.5 \% \mathrm{Nd}: \mathrm{SrY}_{2} \mathrm{O}_{4}$ exhibited the lowest afterglow level among the synthesized samples, and the observed afterglow levels were similar to those of other Nd-doped inorganic materials. ${ }^{(19,38,39)}$ The afterglow levels of the $\mathrm{Nd}: \mathrm{SrY}_{2} \mathrm{O}_{4}$ samples tended to decrease with increasing Nd concentration.

\section{Conclusions}

$\mathrm{Nd}: \mathrm{SrY}_{2} \mathrm{O}_{4}$ single crystals were successfully synthesized by the FZ method, and their PL and scintillation properties were investigated. The synthesized crystals had a single phase of $\mathrm{SrY}_{2} \mathrm{O}_{4}$. Among the samples, $0.1 \% \mathrm{Nd}: \mathrm{SrY}_{2} \mathrm{O}_{4}$ showed the highest PL QY. All the samples exhibited strong emission lines at around 900, 1064, and $1300 \mathrm{~nm}$ in the X-ray-induced scintillation spectra, and their PL and scintillation decay time constants were typical values for the $4 \mathrm{f}-4 \mathrm{f}$ transitions of $\mathrm{Nd}^{3+}$. The $\mathrm{Nd}: \mathrm{SrY}_{2} \mathrm{O}_{4}$ samples exhibited good linearity between the scintillation intensity and X-ray dose exposure in the range from 0.06 to $60 \mathrm{~Gy} / \mathrm{h}$.

\section{Acknowledgments}

This work was supported by Grants-in-Aid for Scientific Research A (17H01375), Scientific Research B (18H03468 and 19H03533), and Early-Career Scientists (18K14158) from the Japan Society of Applied Physics (JSPS). The Cooperative Research Project of the Research Center for Biomedical Engineering and Nippon Sheet Glass Foundation are also acknowledged.

\section{References}

1 T. K. Lewellen: Phys. Med. Biol. 53 (2008) R287.

2 T. Yanagida, Y. Fujimoto, S. Kurosawa, K. Kamada, H. Takahashi, Y. Fukazawa, M. Nik1, and V. Chani: Jpn. J. Appl. Phys. 52 (2013) 076401.

3 S. Kishimoto and T. Yamamoto: Nucl. Instrum. Methods Phys. Res., Sect. A 508 (2003) 425. 
4 K. Yamaoka, M. Ohno, Y. Terada, S. Hong, J. Kotoku, Y. Okada, A. Tsutsui, Y. Endo, K. Abe, Y. Fukazawa, S. Hirakuri, T. Hiruta, K. Itoh, T. Itoh, T. Kamae, M. Kawaharada, N. Kawano, K. Kawashima, T. Kishishita, T. Kitaguchi, M. Kokubun, G. M. Madejski, K. Makishima, T. Mitani, R. Miyawaki, T. Murakami, M. M. Murashima, K. Nakazawa, H. Niko, M. Nomachi, K. Oonuki, G. Sato, M. Suzuki, H. Takahashi, I. Takahashi, T. Takahashi, S. Takeda, K. Tamura, T. Tanaka, M. Tashiro, S. Watanabe, T. Yanagida, and D. Yonetoku: IEEE Trans. Nucl. Sci. 52 (2005) 2765.

5 F. Daghighian, P. Shenderov, K. S. Pentlow, M. C. Graham, B. Eshaghian, C. L. Melcher, and J. S. Schweitzer: IEEE Trans. Nucl. Sci. 40 (1993) 1045.

6 M. Kobayashi, S. Aogaki, F. Takeutchi, Y. Tamagawa, and Y. Usuki: Nucl. Instrum. Methods Phys. Res., Sect. A 693 (2012) 226.

7 T. Yanagida, K. Kamada, Y. Fujimoto, H. Yagi, and T. Yanagitani: Opt. Mater. 35 (2013) 2480.

8 W. Drozdowski, K. Brylew, A. J. Wojtowicz, J. Kisielewski, M. Świrkowicz, T. Łukasiewicz, J. T. M. de Haas, and P. Dorenbos: Opt. Mater. Express 4 (2014) 1207.

9 T. Yanagida, M. Koshimizu, G. Okada, T. Kojima, J. Osada, and N. Kawaguchi: Opt. Mater. 61 (2016) 119.

10 T. Yanagida, M. Koshimizu, Y. Fujimoto, K. Fukuda, K. Watanabe, G. Okada, and N. Kawaguchi: J. Lumin. $191(2017) 22$.

11 T. Yanagida, Y. Fujimoto, M. Arai, M. Koshimizu, T. Kato, D. Nakauchi, and N. Kawaguchi: Sens. Mater. 32 (2020) 1351.

12 D. Shiratori, D. Nakauchi, T. Kato, N. Kawaguchi, and T. Yanagida: Sens. Mater. 32 (2020) 1365.

13 H. Kimura, T. Kato, D. Nakauchi, N. Kawaguchi, and T. Yanagida: Sens. Mater. 32 (2020) 1381.

14 D. Nakauchi, T. Kato, N. Kawaguchi, and T. Yanagida: Sens. Mater. 32 (2020) 1389.

15 P. Kantuptim, M. Akatsuka, and D. Nakauchi: Sens. Mater. 169 (2019) 106401.

16 M. Akatsuka, Y. Usui, D. Nakauchi, G. Okada, N. Kawaguchi, and T. Yanagida: Sens. Mater. 30 (2018) 1525.

17 Y. Fujimoto, T. Yanagida, T. Kojima, M. Koshimizu, H. Tanaka, and K. Asai: Sens. Mater. 28 (2016) 857.

18 M. Akatsuka, D. Nakauchi, T. Kato, N. Kawaguchi, and T. Yanagida: Sens. Mater. 32 (2020) 1373.

19 M. Akatsuka, D. Nakauchi, T. Kato, N. Kawaguchi, and T. Yanagida: Radiat. Meas. 133 (2020) 106298.

20 M. Akatsuka, Y. Usui, D. Nakauchi, T. Kato, N. Kawano, G. Okada, N. Kawaguchi, and T. Yanagida: Opt. Mater. 79 (2018) 428.

21 W. Sun, Z. Zhou, G. Pratx, X. Chen, and H. Chen: Theranostics 10 (2020) 1296.

22 C. Ito, H. Naito, A. Nishimura, H. Ohba, I. Wakaida, A. Sugiyama, and K. Chatani: J. Nucl. Sci. Technol. 51 (2014) 944.

23 E. M. Attas, G. R. Burton, J. D. Chen, G. J. Young, L. Hildingsson, and O. Trepte: Nucl. Instrum. Methods Phys. Res., Sect. A 384 (1997) 522.

24 R. Priya, S. Kaur, U. Sharma, O. P. Pandey, and S. J. Dhoble: J. Mater. Sci.: Mater. Electron. 31 (2020) 13011.

25 J. Philippen, C. Guguschev, and D. Klimm: J. Cryst. Growth 459 (2017) 17.

26 R. Atkins and A. L. Diaz: J. Lumin. 128 (2008) 1463.

27 L. Zhou, J. Shi, and M. Gong: Mater. Lett. 59 (2005) 2079.

28 R. Wei, L. Yang, X. Zhang, X. Tian, X. Peng, F. Hu, and H. Guo: J. Lumin. 228 (2020) 117606.

29 J. Lu, M. Prabhu, J. Song, C. Li, J. Xu, K. Ueda, A. A. Kaminskii, H. Yagi, and T. Yanagitani: Appl. Phys. B: Lasers Opt. 71 (2000) 469.

30 R. A. Fields, M. Birnbaum, and C. L. Fincher: Appl. Phys. Lett. 51 (1987) 1885.

31 A. M. E. Santo, A. F. H. Librantz, L. Gomes, P. S. Pizani, I. M. Ranieri, N. D. Vieira, and S. L. Baldochi: J. Cryst. Growth 292 (2006) 149.

32 T. Yanagida, Y. Fujimoto, T. Ito, K. Uchiyama, and K. Mori: Appl. Phys. Express 7 (2014) 062401.

33 K. Kurosaki, T. Tanaka, T. Maekawa, and S. Yamanaka: J. Alloys Compd. 398 (2005) 304.

34 M. Akatsuka, N. Kawaguchi, and T. Yanagida: J. Ceram. Process. Res. 20 (2019) 280.

35 T. Yanagida, Y. Fujimoto, H. Yagi, T. Yanagitani, M. Sugiyama, A. Yamaji, and M. Nikl: Opt. Mater. 35 (2013) 788.

36 H. Fukushima, D. Nakauchi, T. Kato, N. Kawaguchi, and T. Yanagida: Optik (2021) 238 (2021) 166789.

37 E. Takada, A. Kimura, Y. Hosono, H. Takahashi, and M. Nakazawa: J. Nucl. Sci. Technol. 36 (1999) 641.

38 D. Nakauchi, G. Okada, M. Koshimizu, and T. Yanagida: J. Rare Earths 34 (2016) 757.

39 P. Kantuptim, M. Akatsuka, D. Nakauchi, T. Kato, and N. Kawaguchi: J. Alloys Compd. 860 (2021) 158538. 